\title{
Communication and Cooperation: Technology Transfer on Australian Family Cotton Farms
}

\author{
Dale Gartshore \\ Griffith University, Brisbane, Australia \\ d.gartshore@griffith.edu.au
}

\begin{abstract}
This paper presents findings of a recent study which explores rural women's use of an agricultural decision support system, CottonLOGIC, within the Australian cotton industry. Meta-analysis is applied through the theoretical framework of structuration theory while diffusion theory is used for lower level analysis. The concept of communication is applicable to both theories. The significance of CottonLOGIC as a communication medium for technology transfer of industry research to cotton farms is evaluated in this paper. The findings suggest that CottonLOGIC is a recognised means of information exchange but even more valuable is the cooperation of stakeholders to influence effective reconstruction of farm management practices and technology usage.
\end{abstract}

Keywords: Technology transfer, decision support systems, structuration theory, diffusion theory, communication, farm management, rural, cotton, gender, Australia

\section{Introduction}

The cotton industry in Australia is thriving. Cotton is a valuable export with a consistent annual worth above 1.5 billion dollars. Nevertheless, cotton management is becoming increasingly complex with the need to sustain reliable crop production while making the best use of water and soil resources, utilising effective pest and weed management, as well as limiting environmental impacts (Cotton Yearbook, 2003). Innovative technologies such as agricultural computer-based decision support systems (DSS) are considered a key to the adoption of sustainable farming systems (Hearn \& Bange, 2002). A review of the relevant literature has determined that despite a growing awareness of computers for farm management, there is concern over the limited demand for agricultural DSS. Further, research indicates that farm women are hesitant to use computers for farm management and that their decision-making roles in rural society are unclear.

A recently conducted pilot study investigates the dynamics of women's use of the agricultural decision support software, CottonLOGIC, on Australian cotton farms. Structuration theory is used as a broad theory to explore the recursive notions of structure and technology as the duality of structure and technology. Essentially, the study explores the consequences of technology diffusion on social structures, represented by Giddens (1984) as signification, domination, and legiti-

Material published as part of this journal, either on-line or in print, is copyrighted by Informing Science. Permission to make digital or paper copy of part or all of these works for personal or classroom use is granted without fee provided that the copies are not made or distributed for profit or commercial advantage AND that copies 1) bear this notice in full and 2) give the full citation on the first page. It is permissible to abstract these works so long as credit is given. To copy in all other cases or to republish or to post on a server or to redistribute to lists requires specific permission from the publisher at Publisher@InformingScience.org mation, and on technology using the structurational model of technology by Orlikowski (1992). Diffusion of innovations theory by Rogers (1995), modified for the Australian environmental context by Vanclay \& Lawrence (1995), is used as a lower level theory for analysing technology adop- 
tion or non-adoption. The concepts of homophily and heterophily as defined by Rogers (1995) are applied for a better understanding of the roles of peers and professionals in informing cotton growers of scientific knowledge.

In this paper, the data from interviews with rural women in the cotton industry, both farm women and industry consultants, is analysed and interpreted. Structuration and diffusion theories regard the process of communication as essential for information exchange. This paper sets out to evaluate the extent to which effective communication is vital for transferring new research findings to cotton growers and the role of CottonLOGIC in the communication process.

\section{Background}

Australian farmers are supplementing traditional practices with innovative strategies in an effort to survive recent economic and environmental crises in the rural sector. These innovative strategies include moving towards a knowledge-based farm management style through the use of technology. Stewart (1997), in a case study which explores the gendering of interactive communication technologies (ICTs) in use on Australian family cotton farms, found that farm women's lack of confidence as controllers of data meant that they often avoided responsibility for utilising information systems for decision-making purposes. This was confirmed by Stubbs, Markham \& Straw (1998) in research analysing the use of personal computers (PCs) by farmers for the Australian Rural Industries Research and Development Corporation (RIRDC). All the same, there is evidence that many rural women are increasingly aware of the farm management possibilities of computers for decision-making about new and innovative farming practices.

Alston (1995) argues in her study of the lives of Australian farm women that farm roles have developed based on gender stereotypes. Male farmers are participants in the 'more important' public sphere of outdoor work while farm women have become associated with the less visible private sphere of housework and children. This "domestic work has come to be devalued because it is unpaid and not directly geared to agricultural production and the marketplace" (Alston, 1995, p.24). Nevertheless, rural women are acknowledged as having an ongoing interest in profitable agricultural industries and sustainable resource management. As Rowe (1997, p.44) asserts in the proceedings from the National Forum on Women in Agriculture and Resource Management in Canberra in 1997, women "continue to see the big picture, to assert that we stand on a three legged stool of environment, economics and society, with all legs important and interdependent".

The findings of an Australian report by Bryant (1999) into the impact of PCs on farm management allege that the use of software reflects the traditional gender division of labour on farming properties. Farm women are associated with computer data entry and record-keeping, while male farmers analyse and plan the farm business. Bryant contends that oftentimes the farm woman depends on the male farmer, with his more detailed outdoor farm knowledge, for the input data. If the male farmer is reluctant to provide this data, the farm woman's attempt to use computers for operational and strategic tasks is frustrated. For a more workable and progressive outcome, the report by Bryant recommends that farm men and women work collaboratively to enter data, analyse and interpret it.

Kilpatrick, Johns, Murray-Prior, and Hart (1999, p.7) in Australian studies on the relationship between learning and farm management determine that "to survive, farmers of the future must recognise that farming is more than just a way of life. It is now a high technology, high risk business, requiring access to good information and demanding not only sound business management skills but a higher level of skills than before". The early emphasis of farm management on production planning and financial budgeting has been deemed too limiting. According to Bamberry, Dunn, and Lamont (1997), a comprehensive, whole of farm approach is more appropriate for the multidisciplinary nature of farm management. There is a need for management skills in human 
resources, finances, marketing, risk and change management to compliment traditional skills in crop and livestock husbandry. Most importantly, good farm management relies on the information processing skills of the whole team.

The agricultural DSS investigated in this study is CottonLOGIC. It is an advanced farm management tool being developed by the CSIRO and the Australian Cotton Cooperative Research Centre (CRC), with support from the Cotton Research and Development Corporation (CRDC). CottonLOGIC is a software package of decision support modules to assist cotton growers and their advisors in the management of cotton pests, soil nutrition, and farm operations. It enables the recording and reporting of crop inputs and yields, insect populations, weather data, and field operations such as fertiliser and pesticide applications, as well as the running of insect density prediction and soil nutrition models (CRDC, 2003). The knowledge-based components of CottonLOGIC such as the agronomic models have been developed by researchers for users such as cotton growers, agronomists and consultants.

In agriculture, rural extension services have traditionally been the intermediary between scientific research about farm management, and the decisions that farmers make instinctively. In the 1980s, DSS began to replace extension services in guiding both the farmer and his advisors. DSS were predicted to fill the 'gap' between scientific theory and the real-world practice of farmers (McCown, 2001). Nevertheless their introduction was not unanimously heralded. Cox (1996, pp 362-363) condemns both conventional rural extension and the proposed use of DSS, in particular for the filtering of information:

The substitution of software products as a proxy for direct communication resembles traditional extension: an intermediary is inserted between the communicating parties. The DSS, like extension, filters communication both ways. Use of a product as a substitute for communication stifles it. Participation and communication together provide a more appropriate focus.

Moreover, despite the recognised benefits to agriculture, the principle of science-based intervention, also termed the 'technology-transfer' approach and the 'transfer-of-technology' push, has been criticised extensively (Cox, 1996; Lynch \& Gregor, 2001; McCown, 2001). Vanclay and Lawrence (1995) concede that while technology transfer of scientific knowledge does takes place, that particular model of diffusion is limiting and does not include all aspects of the diffusion process. Cox (1996, p.373) posits that "the tendency for scientific knowledge to override practical knowledge impedes communication." This paper looks at the issues surrounding communication in the diffusion of scientific knowledge to cotton growers through both computer-based and non computer-based channels.

\section{Theoretical Frameworks}

Information systems (IS) are concerned with the "interaction between information technology, individuals, and organisations" (Shanks, Hodgson, \& Darke, 1996, p.1). Increasingly, information systems researchers appropriate theories from other disciplines to enrich their theorising (Lam \& Singh, 2002). For this study, Gidden's structuration theory, a theory borrowed from sociology, is used for meta-theoretical and conceptual applications in a framework put forward by Shanks et al (1996). The conceptual model will provide sensitising concepts such as signification, domination and legitimation for understanding the duality of structure and technology. The meta-theoretical use will be as a broad theory within which other theories such as diffusion theory are placed.

According to Giddens (1984, p.25), "the structural properties of social systems are both medium and outcome of the practices they recursively organise". This central principle of structuration theory refers to the properties of social structures as the result of human actions, which in turn 
reshape human actions. The mutual dependence of human actions and social structures is implied. The recursiveness of social life, as duality of structure, resolves the issue of incommensurability between human interaction and social structure. Essentially, the social reality of cotton farming is constructed and reconstructed when the social institutions and practices of farm management are produced and reproduced. As well, the actor such as the farm woman is socially constructed.

IS issues are never directly discussed in Giddens' writings. Moreover, Giddens has much to say about societies and social relationships of individuals but little about organisations and groups of people (Rose, 2000). Subsequently, Orlikowski (1992) developed a structurational model of technology as an extension of Giddens' structuration theory to reconceptualise the nature and role of technology in organisations. Orlikowski (1992, p. 405) asserts that "technology is created and changed by human action, yet it is also used by humans to accomplish some action". This recursive notion of technology, termed duality of technology, is the critical premise of the structurational model of technology. In essence, an agricultural DSS is both created and changed by human actors such as farm women.

Shanks et al (1996, p.4) posit that "structuration theory is intended as a broad theoretical framework within which other social theories can be located and to which other perspectives can be related". Diffusion of innovations theory by Rogers is an appropriate lower level theory to explore the features of the agricultural DSS within the wider conceptual framework of structuration theory. Rogers (1995, p.5) identifies diffusion as "the process by which an innovation is communicated through certain channels over time among the members of a social system". Rogers explains that for the purposes of diffusion theory, the words 'technology' and 'innovation' are used synonymously. As well, technology has two components, hardware and software. In this study, I concentrate on the software facet which is an agricultural DSS.

Environmental innovations often involve techniques and technologies on a voluntary basis that improve land management rather than increase farm productivity. Costs are often borne by the individual farmer. This is distinct from commercial and production innovations to which the diffusion model was originally applied (Vanclay \& Lawrence, 1995). Therefore, additional attributes are needed to cater for the inadequacies of the traditional diffusion model in the adoption of sustainable resource management technologies, such as an agricultural DSS. The additional features originated from United States rural sociological research by Buttel, Larson, and Gillespie (1990). They were further modified for the Australian environmental context by Vanclay \& Lawrence (1995), as valid reasons for the adoption or non-adoption of a particular technology or management practice. The adapted diffusion model (Buttel et al, 1990; Vanclay \& Lawrence, 1995) is referred to in this paper as the environmental diffusion model. The additional attributes of the environmental diffusion model include divisibility of the product or practice and whether innovations can be partially rather than wholly adopted; and implementation costs, both capital and intellectual outlay. The capital and intellectual expenses for new technology may be substantial and prohibitive, especially during a period of financial crisis when the benefits of the DSS are unclear. Aspects of implementation expense as applied to the concept of communication are examined in this paper.

\section{Research Strategy}

The research design for the study follows the interpretive traditions of IS research. The approach taken assumes that the reality of gender, farming, and technology, such as agricultural DSS, is socially constructed. Consistent with this stance, a subjective and relative approach is adopted. Data collection for the study relies on triangulation and the use of a variety of data sources to enhance rigour and relevance. Data collection is through document analysis, participant observation, and semi-structured, in-depth interviews of women in the Australian cotton industry. A prelimi- 
nary study was conducted in November 2002 in Queensland and northern New South Wales with six (6) women cotton growers and two (2) women cotton consultants for the purpose of validating the data collection methods and the use of the theoretical frameworks. This paper is based on the pilot study. On several occasions, the male farm partners of the women cotton growers participated in the interviews. Their presence appeared not to distract any of the interviewees. In fact, the contributions of the farm partners appeared to enrich both the interview process and the quality of the dialogue. With the preliminary study considered worthwhile, the main field study commenced in June 2003. It is ongoing and expected to be completed by June 2004.

As the subjects of the study, the farm women are expected to offer insights of their experiences as users of farm management software, in particular the agricultural DSS, CottonLOGIC. The farm women are purposefully selected from Australian family cotton farms through a database of CottonLOGIC users and private networks. All the participants demonstrate an awareness of hightechnology and environmentally responsible farming practices.

For the main study, the group of participants will be enlarged to include Australian rural industry professionals such as DSS designers, developers, educators, experimental scientists, research scientists, rural extension officers, agronomists as well as consultants. All these participants have some knowledge of agricultural DSS either through development, usage, research or training. With their in-depth industry knowledge, these participants contribute to the study by being informed observers of the first category.

Documentary data is being collected throughout the study. This data particularly applies to the multitude of information coming in for growers from cotton industry sources. Participant observation has been implemented during attendance at several CottonLOGIC workshops. These qualitative research methods contribute to an understanding of the context of the study even though this paper focuses on data from the interviews.

\section{Communication}

Rogers (1995, p.17) defines diffusion as "a particular type of communication in which the message content that is exchanged is concerned with a new idea". The emphasis in diffusion theory is on the "information exchange" or "technology transfer" since it is essential to communicate if an innovation is to be recognised and adopted. Rogers goes on to explain that most people depend on a subjective evaluation of an innovation from adopters like themselves. The importance of peers in the adoption process confirms the notion of homophily. Homophily is the transfer of ideas between two individuals who are similar in attributes such as social status, education and interests. When individuals share common meanings, the communication of new ideas is regarded as more likely, more effective and more rewarding (Rogers, 1995). In this paper, I regard homophilous communication as occurring between farm partners, family and neighbours. Its opposite, heterophilous communication, occurs between farmers and industry professionals such as rural extension officers, agronomists, consultants, researchers and educators who may apply different meanings to the use of the innovation, such as CottonLOGIC, than do the cotton growers.

Within the environmental diffusion model discussed earlier, implementation expenses, both capital and intellectual, are classified as factors in the adoption or non-adoption of an innovation.

When investigating the intellectual outlay associated with the adoption or non-adoption of a new technology, the situation appears relatively complicated. Within the concept of intellectual outlay, the issues of complexity of the innovation, collaboration by stakeholders, redundancy of effort, and CottonLOGIC course participation are examined in this paper.

Applying the environmental diffusion model, complexity refers not only to an "objective measure of complexity" but to the "knowledge base of a farmer" (Vanclay \& Lawrence, 1995, p.103). 
If the user's level of computer proficiency is low, the task of mastering the software may require an outlaying of disproportionate effort, even to the extent of it not seeming worthwhile.

I came home [after a CottonLOGIC course] and tried to do some things and found I couldn't. I didn't really know where I was going. I still find the program a little bit hard to get along with.

Allied with complexity is the notion of collaboration where farm partners and other stakeholders such as consultants work together to achieve an optimum outcome. In the following scenario, the cooperation of farm partners seems essential in helping to make CottonLOGIC function effectively.

I started setting it up and I found it hard to be able to use it properly, to have each field listed with the correct acres, and everything to each field. It was just something that - I needed my husband - to tell me if I could remember them (laughter). That's like in the too hard basket... to actually get him to sit down and when I suppose I'm wanting to sit down and do it, probably isn't always the time when he wants to sit down and do it. Yeah, so that you're both there at the one time to get it set up.

Informing science can transpire through communication channels other than technological ones. In the following dialogues, verbal communication is practised for informing the farm partner of issues of interest on the Web, fax, electronic and postal mail. This filtering of information demonstrates cooperation by the farm partner who spends time in the farm office rather than in the fields.

Anything I want to know the first thing I do is go on the Internet. Any research whether it's to do with the farm or not and yes because it's getting so late in the season and we haven't had rain to plant the cotton, I've often told him [farm partner] that CSD [Cotton Seed Distributors] have a Web on Wednesday. This week we are talking about this on the Web site and they have that every week and they send me an email each week and this week it's on this topic ... and of course sometimes I forget to tell him what it is. They are having a thing on planting that they ... this morning he said can you get me onto CSD's Website. So he'll get on there this morning to see what they have to say about the different varieties for late planting.

I know when X [farm partner] comes in, I say to him, "what have you been doing?". We sit down. The boys know that when Dad comes in, we have an hour out here, they watch TV, that's their time to watch TV, we're out here and we talk, we have a beer, sit and talk, discuss what's happening. I've done this on the computer, these reports came in, this is what the cotton price is today, it's looking good, someone's faxed us and told us they're offering such and such. I'm informed and if I relay it back to him, it's both of us knowing what's going on.

The growing part of it, Y's [farm partner] the one. I just have to stick it under his nose so that he's aware of it. I open the mail and leave it on his desk. Have you looked through the mail today? I go through it and read it and throw what I know won't ... I know the names of everything but as to how much you put on and all that.

While the cases above illustrate homophilous communication, the ones following testify to the importance of heterophily. The next case is essentially one of a consultant endeavouring to inform a client of the knowledge-based components of CottonLOGIC.

Mainly the insect but I'm also trying to get them onto using the weather data so that we can get more accurate heliothis forecast models that they use in CottonLOGIC. We do use the crop progress reports for emergent ..., one-tree leaf, flowering, peak-flowering, one- 
step boll factor and all that. We're also to start using it for inscription, basically for record-keeping so that we use that and report back to the growers on what to treat the cotton crop with.

Collaboration with industry professionals such as agronomists is a regular and accepted practice for cotton growers. Despite its normality, improvements are sought in existing working arrangements. One woman cotton grower felt that her input, combined with that of their agronomist, would enhance the usage of CottonLOGIC. In addition, the tendency to duplicate tasks would be lessened.

You see, if they [other cotton growers] were able to get that information from their agronomist, download it and bring it up into CottonLOGIC, they would have all that information there to refer to... and you could work your reports on different things.

A recognition of the effort required to collect, enter, and analyse data has been reported in previous papers by the author (Gartshore, 2003, 2004). Many participants openly stated that they had no wish to duplicate tasks by re-keying the insect count data, commonly termed bug-checking data, which was entered into CottonLOGIC at frequent intervals by crop scouts or agronomists. This notion of redundancy is aptly located within the concept of intellectual outlay for this study.

With PAMP [Pesticide Application Management Plan], we've got to have all that communication there. They've [agronomist and aerial sprayer] basically doing the work for us, so I don't see why [we need to use] CottonLOGIC.

Finally, there is the issue of CottonLOGIC training courses which can be considered another means of communication of a heterophilous nature. These courses have been provided annually at no cost to the participants by the CottonLOGIC team to facilitate the use of the software by growers and consultants, as well as to obtain industry feedback.

Yes, it is harder. And really you'd need to go and do the course. I have actually put myself down to go and do a course, but have not got to it because the boys have got sick and that sort of thing.

I was happy enough with the workshop. I think I probably needed a little hands-on before I went so I knew the things I had problems with that I could bring up.

... you go to the basic courses to learn them, which is fine. But you come to a point where you say 'OK, they have another course on but I already know about that'. I would really like a person or someone to come out to me and say this is the problem I'm having here. 'Am I doing that right?'

\section{Duality of Structure}

This section and the following examine the consequences of communication on social structures, represented by Giddens as signification, domination, and legitimation, and on technology using Orlikowski's structurational model of technology. It is important to note, that the separation of social structures into the three dimensions of signification, domination, and legitimation is merely a helpful analytical distinction since the dimensions are inextricably interlinked in practice (Orlikowski, 1992).

Signification is the level of understanding and interpretation and consequently the generation of information and ideology from interpretive schemes. In this study, agricultural DSS provide interpretive schemes which are employed in the cotton industry to record crop inputs and yields, to interpret past results, as well as to predict insect pressures, soil nutrition, and so on, thus enabling 
future plans to be made. Communication, both homophilous and heterophilous, is crucial for transmitting knowledge about the features of CottonLOGIC as well as its novel possibilities.

I think CottonLOGIC, hearing about reports from the growers, and the users, will probably change what they want. Obviously, there's been a demand for the Palm [CottonLOGIC for Palm OS ${ }^{\circledR}$ handhelds] to go in there and check and then they can download it. I think a lot of it coming from your researchers, researchers love it, cause they're using it, and agronomy, bug-checkers.

Domination or power is achieved through drawing on the modalities of facilities and resources which enable or constrain the adoption patterns of human agents. These modalities are identified as allocative facilities such as material and human resources, and authoritative resources that are non-material and are derived from the harnessing of technological and human activities. Material resources include technology such as computer software and hardware. Due to computer advancements in recent years, the power and capacity of this resource has increased significantly. For example, a woman cotton grower claimed that CottonLOGIC gave her the confidence to challenge her farm partner on current field and spray operations, “... for me to sit down there and say, 'OK what's the point of you going that way, if we're not getting any good?'”.

The relationship between technology adoption and the knowledge base of users was recognised by one of the women cotton consultant.

I think a lot of growers do use it. There's also a lot of growers who don't use it. From what I feel, most of the growers are more involved in technology who use the program and who are interested in it. They are really forward thinking people.

That same participant credited her attendance at a CottonLOGIC course for extending her skills.

Yes, I got a lot out of it [CottonLOGIC course]. Because I basically taught myself how to use it, like just going in and mucking around and figuring out what different types were. I really got a lot out of the workshops and just mainly seeing how things worked.

I'm informed and if I relay it back to him [farm partner], it's both of us knowing what's going on.

Legitimation is the level of norms, standards of morality, proper conduct, and traditions that constitute organisational and social structures. For this study, norms include Best Management Practices (BMP) and Integrated Pest Management (IPM) practices widely used within the cotton industry for self-regulatory purposes. Several women recognised that CottonLOGIC assisted them in regulatory record-keeping for BMP and IPM. As one woman confidently stated:

Well, while you're BMP you're supposed to have your records of exactly what you are doing. People could be using it as a way of keeping track of all of their field preparations because it's got all that in it as well.

So that when we come to the end of the season, we can print up what sprays that paddock has had, how much it costs. Because with InGard, we have to have costings of all the sprays we used. You have to compare it with conventional costs. We have BollGard too this year so you have ... that data is important because it saves reefing through all the agronomy sheets, there's about a hundred of them.

\section{Duality of Technology}

Orlikowski points out that people can (even if they do not) redefine the meaning, properties, and applications of a given technology after development. One consultant had given some thought as to how she could enhance the use of CottonLOGIC to benefit her clients, the cotton growers. 
There is a way we can use it to track what we recommend and what the grower actually applies. In the spray section, you can do an order form and you can do an application like there are two parts to it. We're thinking that when we do a recommendation, we can use the order. And when the grower actually applies the spray, we use the application. So that we have both sides. It's different, what we recommend and what they actually apply. It's for better record-keeping.

One of the more resourceful comments in the study came from a woman cotton grower who was technically very competent but had hesitated to use CottonLOGIC because of not wanting to duplicate previous effort. She clearly felt that collaboration between cotton growers and agronomists was essential.

To be able to import it [bug-checking data] into CottonLOGIC would be great. If they [agronomists] could send me their information each month...so that I could pull it in and use it for my purposes...I really think that would be a great idea and I think then you'd find a lot more cotton growers would use it

If the agronomist could email me what they've put in about our block...I asked Y [agronomist] could she do that, and she said 'I can't split up my clients. I would have to send you all my clients' stuff, not just you'. You see, I thought if she could give us all the information about us as a client. That is just a simple thing. But that way, we wouldn't be doubling up. What's the point of their [agronomists] putting it [insect count data] all in, and me putting it all in, when we could work together. I could get that information and then I could utilise the other things [the other features of CottonLOGIC such as forecasting pest pressures].

\section{Discussion}

This paper has examined the process of communication in informing cotton growers of the latest science available from research. The analysis has been performed through a theoretical framework which includes structuration theory and the concept of intellectual outlay from the environmental model of diffusion. Even though the focal point of the study is the agricultural DSS, CottonLOGIC, nevertheless the cotton industry engages other channels of communication such as verbal, fax, Web-based, electronic and standard mail. Yet, while the communication process is vital for information exchange, without cooperation from farm partners and industry professionals, described as homophilous and heterophilous associations respectively, there would be fewer opportunities to translate new knowledge from scientific research into changing practices for both farm management and technology usage. These recreations of farming structures and technologies mean that cotton growers are better informed particularly for managing costs of production and improved sustainability.

As well, evidence from the pilot study indicates that the filtering of information in the communication process is a valuable and effective device for avoiding information overload and for drawing the attention of farm partners to issues of real importance. Furthermore, in response to the following statement by Cox (1996, p.374) that the "...provision of a DSS becomes a substitute for communication, rather than contributing to the identification, development and realisation of novel possibilities", the findings suggest that CottonLOGIC users do not regard a DSS to be a substitute for communication. Rather, it is considered to be just one of several mediums for communicating research findings to the cotton fields. Nevertheless, the findings indicate that DSS usage does evoke new possibilities for the user, especially when the cooperation by stakeholders is forthcoming.

Despite the acknowledged intellectual costs, the benefits of using CottonLOGIC were recognised. For instance, many participants expressed an appreciation of the value of the information yielded 
from the insect count data for insect management. One interviewee, who was highly computerliterate, suggested that maybe it would be feasible to collaborate with the agronomist so that the insect count data could be regularly emailed to each interested cotton grower. If individual growers could download the data into CottonLOGIC, they could then manipulate the data to generate customised status reports and graphs for predicting pest pressures and yield losses. This questioning of existing software application is an illustration of the recursive nature of technology, otherwise referred to as the duality of technology, where technology is both a medium and a product of human activity.

Regarding the other notion of duality, the duality of structure, evidence from the pilot study suggests that the use of CottonLOGIC reinforces, modifies and alters farm management practices in the family farm enterprise. Correspondingly, cotton growers activities, in particular those of the women, are being reshaped by the construction and reconstruction of these changing farming practices. In effect, the use of CottonLOGIC by farm women appears instrumental in augmenting their level of awareness, understanding, and interpretation, thus providing them with confidence to challenge existing practices.

\section{Conclusion}

Using data from a recently conducted pilot study in the cotton industry, this paper analyses communication in the technology transfer process of scientific research findings to cotton growers and their advisors. Communication, and the issues of complexity of the innovation, collaboration by stakeholders, redundancy of effort, and CottonLOGIC course participation relate to the notion of intellectual outlay from the environmental model of innovation diffusion. These concepts are explored through the three dimensions of signification, domination, and legitimation from Giddens' model of structuration (duality of structure), as well as Orlikowski's structurational model of technology (duality of technology). In summary, the research found that good communication, both computer-based and non computer-based, is essential for information exchange but even more valuable is the cooperation of stakeholders to influence effective reconstruction of farm management practices and technology usage.

It is apparent that the advantages of using a decision support and farm management software tool such as CottonLOGIC are noteworthy, in particular for assisting farm women to overcome existing constraints by establishing greater awareness of farm management operations and strategies. Further, the women are empowered by increasing confidence to contribute in enterprising ways to a greater range of farm management tasks such as those related to industry self-regulation. From this application, emanates proposals for using CottonLOGIC innovatively through collaboration with cotton advisors and farm partners, thus facilitating an optimum industry outcome. This study affirms the words of Cox (1996, p.376) in that "the criteria for success ... should relate to the critical insights gained through improved communication of the different perspectives of researcher and farmer".

The cotton industry endorses the use of innovative technologies to inform science to users; the anticipated outcome being the enhancement of sustainable farming systems. DSS is one such technology used in the communication process. This study, as well as the main study now in progress, in seeking to better understand the constructs associated with the implementation of CottonLOGIC, particularly by rural women, has the potential to generate improved resource management on family cotton farms with flow-on benefits to the Australian rural sector. 


\section{Acknowledgements}

The author would like to thank her PhD supervisors, Dr Sue Nielsen and Dr Don Kerr from Griffith University and Dr Mike Bange from the CSIRO. Their encouragement and constructive comments are always appreciated.

\section{Glossary of Terms and Abbreviations}

BMP Best Management Practices is a voluntary environmental program which requires specific standards of farming

Bollgard II Cotton genetically modified with two genes Bt to produce a natural pesticide to control the heliothis pest

DSS Decision support system is a computer-based information system for supporting and improving decision-making

Ingard Cotton genetically modified with single gene $\mathrm{Bt}$ to produce a natural pesticide to control the heliothis pest

IPM Integrated Pest Management is a management practice to reduce the amount of insecticide used on a crop

\section{References}

Alston, M. (1995). Women on the land: The hidden heart of rural australia. Kensington, NSW: UNSW.

Bamberry, G., Dunn, T., \& Lamont, A. (1997). A pilot study of the relationship between farmer education and good farm management. Canberra, ACT: Rural Industries Research \& Development Corporation (RIRDC).

Bryant, D.L. (1999). Computers on the farm: Farmers' usage patterns and impact on farm management. Canberra, ACT: Rural Industries Research \& Development Corporation (RIRDC).

Buttel, F.H., Larson, O.F., \& Gillespie JR, G.W. (1990). The sociology of agriculture. Connecticut, USA: Rural Sociology Society.

Cox, P.G. (1996). Some issues in the design of agricultural decision support systems. Agricultural Systems, $52(2 / 3), 355-381$.

Cotton Yearbook 2003 (2003). Toowoomba, Qld: The Australian Cottongrower.

CRDC (2003). Spotlight. Narrabri, NSW: Cotton Research \& Development Corporation.

Gartshore, D. (2003). Divisibility and duality: Rural women and farm management in the Australian cotton industry. Proceedings of the 8th National Labour History Conference. Brisbane, Qld.

Gartshore, D. (2004). "What's the point?" Women's view of diffusion and duality of a decision support tool in the Australian cotton industry. Forthcoming in the proceedings of the IFIP International Conference on Decision Support Systems (DSS2004). Prato, Tuscany, July 2004.

Giddens, A. (1984). The constitution of society: Outline of the theory of structuration. Berkeley and Los Angeles, USA: University of California Press.

Hearn, A.B., \& Bange, M.P. (2002). SIRATAC and CottonLOGIC: Persevering with DSSs in the Australian cotton industry. Agricultural Systems, 74 (1), 27-56.

Kilpatrick, S., Johns, S., Murray-Prior, R., \& Hart, D. (1999). Managing farming: How farmers learn. Canberra, ACT: Rural Industries Research \& Development Corporation (RIRDC). 
Lam, D., \&. Singh, D.M. (2002). A conceptual model to study the diffusion of the Internet in Vietnam. Proceedings of the 13th Australasian Conference on Information Systems. Melbourne, Vic.

Lynch, T. \& Gregor, S. (2001). Technology-push or user-pull? The slow death of the transfer-of-technology approach to intelligent support systems development. Socio-technical and human cognition elements of information systems. School of Computing and Information Systems, Central Queensland University.

McCown, R. L. (2001). Learning to bridge the gap between science-based decision support and the practice of farming: Evolution in paradigms of model-based research and intervention from design to dialogue. Australian Agricultural Research, 52, 549-571.

Orlikowski, W. (1992). The Duality of technology: Rethinking the concept of technology in organisations. Organisation Science, 3 (3), 398-427.

Rogers, E.M. (1995). Diffusion of innovations (4th ed.). New York, USA: The Free Press.

Rose, J. (2000). Information systems development as action research - Soft systems methodology and structuration theory. (Doctoral dissertation, Management School, Lancaster University, England).

Rowe, F. (1997). Women contributing to agriculture and resource management. Proceedings of National Forum on Agriculture and Resource Management, Canberra, ACT: Standing Committee on Agriculture and Resource Management.

Shanks, G., Hodgson, B., \& Darke, P. (1996). The use of structuration theory in information systems research. Proceedings of the 7th Australasian Conference on Information Systems. Hobart, Tasmania.

Stewart, J. (1997). I don't touch it without the cook here: A case study of gender and technology on family cotton farms. (Doctoral dissertation, Department of Sociology and Anthropology, University of Queensland, Brisbane).

Stubbs, A.K., Markham, N.R., \& Straw, W.M. (1998). Personal computers for farmers: Current and future use. Canberra, ACT: Rural Industries Research \& Development Corporation (RIRDC).

Vanclay, F., \& Lawrence, G. (1995). The environmental imperative: Eco-social concerns for Australian agriculture. Rockhampton, Qld: Central Queensland University Press.

\section{Biography}

Dale Gartshore is currently on a full-time academic appointment with the Griffith Business School at Griffith University while undertaking her PhD into the structuration of women's use of farm management software in the Australian cotton industry. She is an active member of the women's industry network group in cotton (WinCott) whose role includes strengthening the links between research and government, and the women in the cotton industry.

Earlier studies by Dale were achieved in part-time mode due to the demands of a young family. During that period, she gathered practical experience as an owner operator of the family cattle property. As well, during that period Dale gained an Unrestricted Private Pilot licence. Her experiences as a woman pilot in the world of aviation, led her to join the Australian Women Pilots' Association (AWPA) of which she became State President, State Treasurer, Librarian and WebMaster over the course of ten years.

Prior to 1980, Dale worked as a computer programmer and analyst. She was employed in a permanent Government position in Canberra and later as a freelance contractor in the UK for multinationals such as Burmah-Castrol, Bayer Chemicals, and the Bank of America. Back in Brisbane, Dale worked as a systems engineer for Facom Australia. 